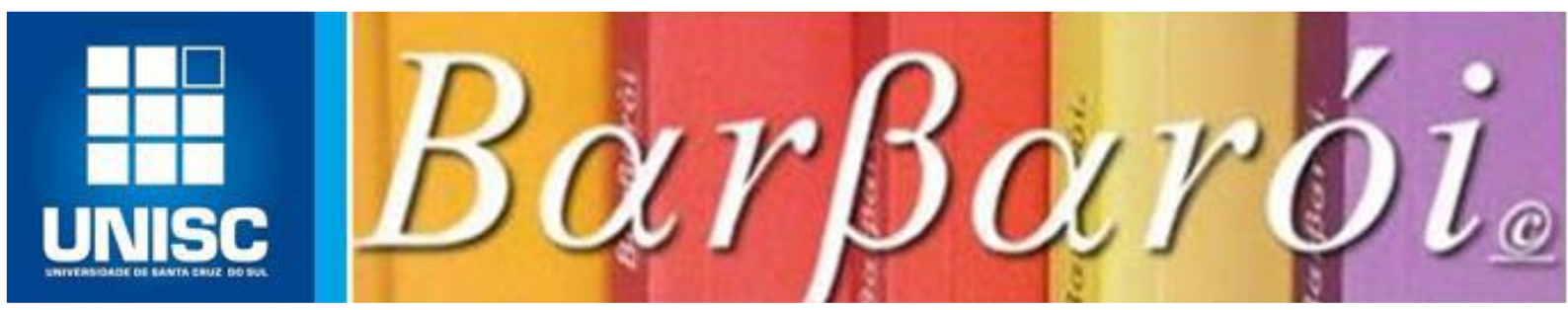

\title{
RELAÇÕES SOCIAIS E REDES DE APOIO NA ADOLESCÊNCIA: EXPERIÊNCIAS MEDIADAS PELA MÚSICA
}

\author{
DOI: http://dx.doi.org/10.17058/barbaroi.v0i58.4107 \\ $*$
}

\author{
Janaina de Fátima Zdebskyi \\ Universidade do Vale do Itajaí - UNIVALI - Brasil \\ Carlos Eduardo Máximo \\ Universidade do Vale do Itajaí - UNIVALI - Brasil \\ Ulysses Thiago Batista Pereira \\ Universidade do Vale do Itajaí - UNIVALI - Brasil \\ $*$
}

\begin{abstract}
Resumo
O presente artigo resulta de uma pesquisa intervenção de cunho qualitativo, realizada com quinze adolescentes de uma instituição localizada litoral norte de Santa Catarina. Para coleta de dados foram realizadas oficinas musicais, nas quais os participantes escolheram letras de músicas para abordar questões a respeito de sua condição de vida, discorrendo sobre o território onde vivem, a percepção que têm de si e do tempo e sobre as suas redes sociais de apoio. Em um corte temático para efeitos deste artigo, as redes sociais de apoio foram eleitas como a temática a ser analisada e discutida por meio da análise temático-categorial. Os resultados apontaram para um espaço escolar com uma função indefinida, pautado na contestação das regras e normas que são impostas, onde ocorrem brincadeiras e intrigas. Quanto à rede de amigos, observou-se que essa relação é baseada nos sentimentos de confiança e de lealdade, se configurando como uma rede essencial nesse ciclo da vida, assim como a família que se apresenta como um fator de proteção, mesmo perpassando situações conflituosas, de violência, mortes e separações.
\end{abstract}

Palavras-chave: adolescência; condição de vida; redes sociais de apoio; música.

\section{Introdução}

O título que propõem-se nesse artigo parte do principio de que a forma como o(a) adolescente age e se define é constituída por sua relação com seus pares; por suas atividades cotidianas, seus projetos, pelo lugar/território onde vivem, por sua relação com o tempo, pela 
forma que utilizam para expressar essas percepções e também pelas redes de apoio social e as relações afetivas que se estabelecem nelas.

As redes sociais de apoio constituem ainda as características especificas da adolescência, para Ozella (2003), esse é um período que envolve transformações, formação dos valores próprios e da identidade, configurando-se em um momento crucial para o desenvolvimento humano. Entende-se a adolescência como um processo de constituição com determinações históricas, culturais e sociais que resulta na produção das singularidades no homem que se constrói em meio à sua realidade e nas relações - incluindo com as redes sociais de apoio - que se estabelecem nesse período.

Existe uma compreensão simplificada por parte da sociedade a respeito da adolescência, considerando aqueles que estão vivenciando essa fase como imediatistas, consumistas, desinteressados, individualistas, irresponsáveis e alienados diante dos fatos (SILVA, 2009). Não se considera a condição de vida que cerca esses(as) adolescentes, que é constituída por fatores sociais, culturais e econômicos, os quais compõem o contexto onde o sujeito está inserido, estando presentes em seu cotidiano e constituindo suas experiências (IBGE, 2010).

Em diferentes espaços desta sociedade há um debate intenso sobre os problemas relacionados com a adolescência. Nesses apelos, geralmente mobilizados pela mídia, dá-se visibilidade a adolescência pelos efeitos dos momentos de contradição entre práticas juvenis de violência, abandono escolar, indisciplina e as normas instituídas socialmente. Dado que tem gerado um clamor por mais controle e menos direitos civis, como é o caso de Propostas de Emenda Constitucional para redução da maioridade penal. Frequentemente ausente deste debate é a discussão de como se constitui o(a) adolescente? Qual fenômeno é este? Como se apresenta na realidade brasileira?

Na busca por dados a respeito da condição de vida dessa população, nos deparamos com alguns indicadores sociais, os quais são: educação, habitação e saneamento, desenvolvimento social, mercado de trabalho e saúde (IBGE, 2010). Ao tomarmos tais indicadores, levantamos dados em nível municipal. A situação de vida dos jovens e crianças em Itajaí perpassada pelas denúncias acolhidas pelo Conselho Tutelar do município que retrata no ano de 2011 a ocorrência de 804 casos de violência física e 71 atendimentos de violência sexual, sendo 21 deles procedentes. De janeiro a março de 2012 foram notificados 4 casos de violência física, 42 de violência psicológica, 19 suspeitas de violência sexual, 66 solicitações de vagas em escolas, 4 casos de desnutrição, 65 de negligencia, 11 casos de falta 
de condições de sobrevivência, 67 de conflito familiar, 4 casos de exploração no trabalho e 39 de maus tratos. Estes elementos locais que têm provável reciprocidade em outros municípios do país não ganham a mesma visibilidade que as ações conflitivas que se estabelecem entre os adolescentes e a sociedade.

É preciso considerar que essa condição de vida na adolescência e mesmo questões como o acesso à educação, ao lazer, a alimentação de q

ualidade e a exposição à situações de violência estão bastante atreladas a questão econômica da família/cuidadores, por isso, é importante informar que no casso da presente pesquisa estamos abordando como recorte as perspectivas de adolescentes em condição socioeconômica desfavorável, atendidos(as) pela instituição que nos recebeu para pesquisa de campo. Além disso, o foco se deu sobre as perspectivas desses(as) adolescentes sobre sua condição de vida, principalmente sua percepção sobre redes sociais de apoio em que estão inseridos(as).

O projeto de pesquisa foi avaliado e aprovado pelo Comitê de Ética em Pesquisa, sendo de cunho Qualitativo, utilizando-se dos preceitos da pesquisa e intervenção que consiste em uma tendência das pesquisas participativas que visa investigar a vida de coletividades na sua diversidade qualitativa, permitindo a intervenção de caráter socioanalítico (ROCHA; AGUIAR, 2003 apud DELL'AGLIO; SANTOS, 2008). Nesse processo, a relação entre pesquisador e objeto pesquisado é dinâmica e define os caminhos da pesquisa que é uma produção do grupo envolvido. Sendo assim toda investigação psicológica implica em uma intervenção, na qual o participante e os(as) pesquisadores(as) são afetados pela situação (SZYMANSKI; CURY, 2004 apud DELL'AGLIO; SANTOS, 2008).

Para coleta de dados foram entrevistados 15 adolescentes com idades entre 12 e 13 anos, participantes de uma instituição filantrópica de uma cidade do litoral norte de Santa Catarina. Esses sujeitos faziam parte de uma das turmas da instituição, a qual teve disponibilidade de horário para participar da pesquisa, tendo como critério de participação ter matricula regular na instituição.

No primeiro contato com o grupo foi realizada a aplicação de uma anamnése para caracterizar o sujeito participante da pesquisa, abordando questões a respeito do gênero, idade, escolaridade, tempo de participação na instituição, renda média mensal familiar e composição familiar do(a) adolescente.

Posteriormente, foram realizados três encontros no formato de Oficina de Expressão Musical. Nesta oficina foi sugerido aos participantes que a cada encontro levassem a letra de 
uma música que consideravam ter relação com sua vida. Durante os três encontros, as letras das músicas escolhidas foram discutidas e aprofundadas com os participantes do grupo.

A forma de registro utilizada nos encontros foi a gravação de áudio e vídeo, antecipadamente informada e autorizada pelo sujeito participante. As gravações foram transcritas para serem utilizadas na pesquisa e os nomes de cada participante foi mantidos em sigilo, substituídos por nomes fictícios.

No quarto encontro utilizou-se a técnica de entrevista coletiva aberta, com vistas a compreender os sentidos atribuídos pelos(as) adolescentes diante do processo experimentado nas oficinas de expressão musical e identificar os pontos de vista consensuais e divergentes entre os(as) participantes, provocando o debate e o pensamento crítico nos mesmos.

A entrevista foi analisada em conjunto com a análise das oficinas de expressão musical. A música foi escolhida como facilitadora das oficinas, visto que foram encontrados relatos de sua utilização em outras pesquisas, entre estas, a de Groff (2010) e de Wazlawick (2010). Tomando essas pesquisas como base para o presente estudo, a música foi compreendida como um modo de sentir e pensar que permite criar emoções e inventar linguagens, agindo como fruto de um processo criador onde o sujeito articula percepção, imaginação, reflexão, sentimentos e emoções. Enquanto o sujeito produz esta objetividade, produz a si mesmo, em um movimento de (re)criar-se como sujeito, partindo da transformação do que já existe. Desta forma, a música é uma subjetividade objetivada, traçada por sujeitos que inscrevem nela suas marcas, sua presença, articulada no plano da afetividade, situada historicamente e compreendida como sendo também um trabalho acústico. (MAHEIRE, 2001, 2003; HINKEL, 2010 apud WAZLAWICK, 2010)

Como referencial metodológico para análise dos dados utilizou-se a análise temáticocategorial, na qual os dados coletados foram estudados e divididos em unidades de registro por temas e esses resultados foram discutidos com base em um olhar teórico especifico (OLIVEIRA, 2008). Procuramos utilizar trechos de falas com um potencial indexador daquilo que foi referido pelos(as) adolescentes durante as oficinas e entrevistas coletivas, para esse fim alguns recortes foram mantidos em sua integralidade por tratarem de eventos que corroboravam com histórias comuns dos demais participantes.

Considerando os dados coletados e a apreciação dos mesmos, para efeitos deste artigo, os fatores constatados que estão implicados na adolescência e em sua condição de vida foram selecionados por meio de um corte temático. Os(as) pesquisadores(as) elegeram as redes sociais de apoio para serem discutidas e analisadas conforme aparecerá nas falas dos 
adolescentes que participaram da pesquisa. Sendo assim, essa temática foi explorada com base nos relatos dos adolescentes sobre a escola, as relações de amizade e a família, assim como aborda-se no presente trabalho.

\section{O papel das redes sociais de apoio na condição de vida de adolescentes}

A rede social de apoio configura-se como as redes próximas e significativas de relações do sujeito, estas representam o apoio percebido e recebido pelo mesmo. Essas redes se constituem como um fator de proteção importante, essencialmente nas primeiras fases do desenvolvimento humano e podem ser compostas por diferentes conjuntos de pessoas, como a família, os amigos, a escola, a comunidade, entre outros, capazes de oferecer apoio para que o adolescente crie estratégias adequadas para lidar com situações adversas no decorrer de sua vida (COSTA 2009).

As redes sociais de proteção interagem com os fatores de risco de forma a proporcionar alternativas para resolução de conflitos. Sendo assim, considera-se como função das redes de apoio social:

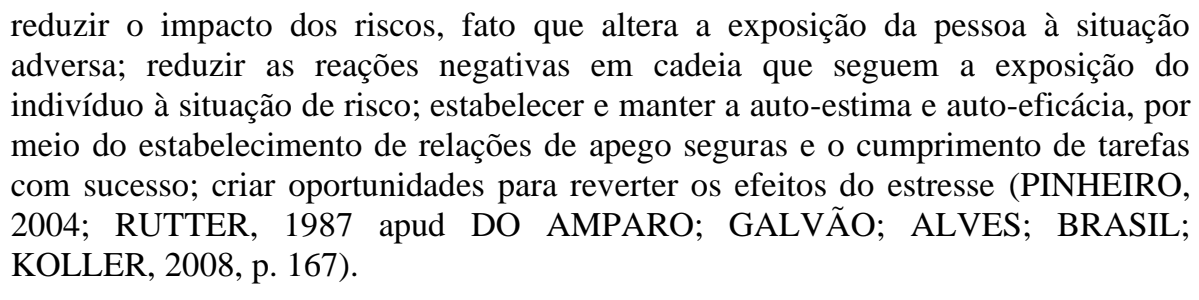

Dentre as redes de apoio que foram citadas nas falas dos(as) participantes durante as oficinas realizadas, foi abordada a escola e os conflitos, intrigas e brincadeiras que se estabelecem nesse espaço; os grupos de amigos e as relações com essa rede que é baseada nos sentimentos de confiança, compartilhamento de experiências e de atividades de lazer e, a família, envolvendo sua configuração, os conflitos e separações que permeiam as relações familiares.

\section{Escola}

Eu tô aqui pra quê?

Será que é pra aprender?

Ou será que é pra sentar, me acomodar e obedecer? Tô tentando passar de ano pro meu pai não me bater Sem recreio de saco cheio porque eu não fiz o dever A professora já tá de marcação (...)

(Trecho da música Estudo errado - Gabriel O Pensador) Barbarói, Santa Cruz do Sul, n. 58, p.<08-29>,jan/jun 2021 
A escola é considerada um espaço com dimensão física e psicológica, um contexto social onde se estabelecem diferentes relações. Esse espaço multicultural inclui sujeitos com características diferentes e inúmeras interações contínuas e complexas relacionadas com os diferentes estágios de desenvolvimento do aluno. Nesse espaço, também estão presentes diferentes conhecimentos, atividades, regras e valores, que são permeados por situações de conflitos, problemas e diferenças (DESSEN; POLINIA, 2007).

Siqueira (2009) afirma que a escola, muitas vezes, se mantém distante de questões sociais e familiares e desta forma não exerce o papel de apoio social e afetivo que deveria exercer, principalmente para jovens em condições de vida desfavoráveis. A mesma autora constatou que existe uma relação bastante frágil entre o jovem e sua família com a instituição escolar; uma relação baseada em desvalorização da escola por parte dos familiares, falta de assiduidade escolar e no sentimento de rejeição escolar.

Nas falas dos participantes sobre o contexto escolar, percebe-se a presença desses sentimentos de desvalorização, visto que a escola não foi abordada como ambiente educacional de formação, mas sim como o ambiente onde ocorre a bagunça, a desordem e as brincadeiras, entre os colegas e com os professores. Esses professores são descritos pelos participantes da seguinte de forma:

Maria Bethânia: A minha professora é dentuça, ela fica que nem um coelho na sala. Ano passado a gente tinha um professor que dava aula de português que pegou uma carteira e colocou na minha frente, daí ele falou bem assim pra carteira "você vai ser um ótimo aluno", quando ele falava com a gente ele cuspia na gente, a gente falava "olha não precisa molhar a gente, a gente tomou banho antes de vir pra escola”. Ele ficava que nem um retardado lá na frente e a gente chamava ele de pastor.

Pesquisador(a): Por que?

Maria Bethânia: Porque tudo o que ele falava ele incluía a família dele, ele saia da matéria pra falar da vida pessoal.

Pesquisador(a): O que tu acha disso?

Maria Bethânia: É um retardado, eu até saia da sala sem pedir.

As características citadas pelos adolescentes sobre o contexto escolar (a bagunça, as brincadeiras e os desentendimentos com os professores) são vistos pelos participantes como algo "legal", sendo que os mesmos relatam gostar do espaço de suas salas de aula: 
Gal Costa: A gente faz muita doideira, meu deus do céu. (...) Doideira é comigo mesmo. Doideira é gostar de jogar carteira, fazer bagunça, uma vez eu escrevi no quadro, e comecei a escrever e apagar no quadro, escrever palavrão.

Maria Bethânia: Oh só pra tu ter uma noção, a nossa sala vai ser a primeira sala que vai ter reunião por causa que os professores não conseguem dar aula, desordem. Olha professora, meu deus, amanhã se for bagunça eu vou lá na diretoria reclamar. (...) Porque daí o que que acontece, a gente fica em recuperação, roda de ano, não tem a matéria, e é tudo por causa de 15 guri, e agora mais 15 guria.

Chico Buarque: A minha sala é baita legal, eu vivo indo para secretaria.

A postura que os entrevistados apresentam com relação aos seus professores e cotidiano escolar corrobora com a visão de Dayrell (2007), que analisa as mudanças na relação entre alunos e professores, destacando a questão da autoridade, visto que esta já não é mais natural, óbvia e legitimada no papel de professor, mas pelo contrário, precisa ser construída na relação professor-aluno e legitimada pelos jovens.

A respeito do ambiente da sala de aula, o mesmo autor considera esse espaço como um lugar de tensões entre o ser jovem e o ser aluno. Nesse contexto, o sujeito presencia alianças e conflitos com os colegas e professores, relações estas que são regadas por imposições de normas e estratégias individuais e coletivas de transgressão. Nesse sentido, o jovem aluno vivencia uma via de mão dupla, entre a escolha de seguir as regras escolares, cumprir as demandas exigidas pelos docentes e ser o aluno exemplar ou afirmar a subjetividade juvenil pautada nas interações, posturas e valores dos pares. Assim, o sujeito no contexto escolar passa por uma busca de integrar-se ao sistema simultaneamente afirmando a sua individualidade, como sujeito e jovem (DAYRELL, 2007)

Ainda, ao falar sobre as brincadeiras que acontecem no cotidiano da sala de aula, Maria Bethânia diz que gosta dessas situações, porém faz algumas ressalvas:

Maria Bethânia: Ah! Eu gosto, só que eu não passo a minha cabeça no quadro, porque um monte de gente faz isso, eu não jogo bolinha de papel eu não como chiclete mascado dos outros.

Pesquisador(a): Tem gente que faz isso?

Maria Bethânia: Aham, só por causa do amigo da onça.

Caetano: Amigos da onça?

Pesquisador(a): Como que é essa brincadeira? Tu pode me explicar? 
Maria Bethânia: É assim, eu te desafio a andar engatinhando pela sala todinha cinco vezes, daí tem que andar, daí a gente vai lá e chuta o bunda da pessoa.

Diante dessas falas, percebe-se uma relação do adolescente com o contexto escolar cercada pela contestação das regras estabelecidas nesse espaço, e ao mesmo tempo com a instituição de regras próprias do grupo nas brincadeiras, aqueles que não às seguem são punidos apanhando de régua na bunda. Essa contestação das regras escolares gera a bagunça, as reprovações, as brincadeiras entre os pares e com os professores, em situações que mais uma vez estão presentes os estereótipos de um professor sério, uma secretaria que estabelece ordem, regras e punições.

Considerando que as brincadeiras e intrigas são relatos frequentes dos participantes a respeito do contexto escolar, percebe-se que esses fatores refletem o desinteresse dos alunos a respeito da suposta função da escola de propiciar conhecimento. Assim, considera-se que o modelo atual das escolas brasileiras se encontra distante da realidade e dos interesses dos jovens, os professores acrescentam pouco à formação dos mesmos, fazendo com que frequentar a escola se torne cada vez mais uma obrigação para conseguir o diploma, um mero pedaço de papel que não significa ter o conhecimento. Na relação entre o contexto escolar e a juventude é possível perceber uma escola que reduz o jovem ao seu título de "aluno" e se afasta de compreender a diversidade étnica, de gênero, de orientação sexual ou outras expressões de subjetividade que caracterizam a condição juvenil e de sujeitos singulares, uma crise movida por questionamentos de professores(as) e alunos(as) se perguntando a que a escola se propõe realmente (DAYRELL, 2007).

Considerando os sentidos presentes nas falas dos(as) adolescentes, identifica-se o ambiente escolar como um contexto provedor de interações com a rede de amigos, um espaço permeado por brincadeiras e contestações de regras e normas. Diante disso, questiona-se qual seria a função da escola como rede social de apoio para seus alunos, função esta - que segundo os resultados obtidos na pesquisa - vem se mantendo em segundo plano no cotidiano escolar.

Desta forma, se faz necessário gerar reflexões sobre a importância de transformações no contexto escolar e mesmo das percepções dos(as) estudantes e cuidadores sobre a função desse espaço. A escola precisa ser transformada em um local pautado na singularidade e nas especificidades da juventude brasileira de hoje. É preciso resgatar - ou reconstruir - o significado da escola, a função e lugar que ela ocupa na vida dos jovens (DO AMPARO; GALVÃO; ALVES; BRASIL; KOLLER, 2008) e para isso, o primeiro passo é ouvir essa 
juventude por meio das mais diversas instâncias em que ela está organizada, seja pelas organizações de movimento estudantil, como grêmios escolares e Uniões Municiais e Nacional de Estudantes Secundaristas, mas também pelos Conselhos, como os Conselhos Municipais de Juventude, que tem justamente por objetivo a construção de políticas públicas com ampla participação popular.

\section{Amigos}

Lágrimas na vitória Sempre na derrota ou glória

(...) A amizade é tudo!

É se dar sem esperar Nada em troca dessa união

É ter alguém pra contar $\mathrm{Na}$ indecisão!

Nunca se desesperar

Sempre ali pra estender a mão

Maior valor não há! É feito irmão!

(Trecho da música A amizade é tudo - Jeito Moleque)

A amizade é uma relação intima, espontânea e recíproca entre pessoas, onde está presente uma carga afetiva. Na adolescência a amizade desempenha a função de provedora de bem-estar subjetivo e suporte social, fazendo possível compartilhar experiências, interesses, sentimentos e emoções que são intensamente vivenciadas pelos adolescentes. Além disso, a relação de amizade propicia o aprendizado de habilidades sociais importantes ao longo da vida (BORSA, 2013). Essas características sobre amizade se destacaram nas falas dos adolescentes durante as oficinas, eles falam da relação de confiança, apoio e proximidade com os pares:

Marisa Monte: amigo para mim não é só nas horas boas, é para quando a gente está triste, quando precisa desabafar ou tirar alguma dúvida.

Luiz Gonzaga: Amigo é a pessoa que tu pode compartilhar o que tu tem com ela.

Maria Rita: amizade é praticamente tudo, a gente pode ter amizade em qualquer lugar, em casa podemos ter amizade com nossos pais, na escola, na instituição e eu gosto do refrão que é assim "lagrimas na vitória, sempre na derrota ou glória” (trecho do refrão da música "amizade é tudo" do Jeito Moleque) 
Nessas colocações constata-se uma visão comum dos adolescentes no que diz respeito à amizade, descrevendo-a como uma relação baseada no apoio mutuo (para desabafar, compartilhar e tirar dúvidas), estando presente na vida em diferentes momentos e lugares.

Referindo-se a essas características, o artigo de Do Amparo; Galvão; Alves; Brasil e Koller (2008), constatou que a grande maioria dos entrevistados (96,3\%, 92,8\% e $96.1 \%$ respectivamente) afirma ter amigos, que esses amigos devem dar apoio emocional e que os amigos podem "contar" com o entrevistado. Os adolescentes envolvidos na pesquisa também possuem falas que se aproximam dos dados constatados acima, quando afirmam considerar seus amigos como àqueles que estão sempre próximos - em momentos bons e ruins - e com os quais podem conversar e compartilhar experiências e o sentimento de confiança. Identificam-se também situações de intrigas e desentendimentos nas relações de amizade:

Maria Rita: tipo a gente ficou sem se falar e começamos a chorar, dai a gente tava numa derrota.

Maysa: é que tava eu ela juntos, e dai de repente apareceu uma menina nova, dai eu fiquei conversando só com ela, dai ela ficou toda ciumenta e ficou brava.

Essas situações de intrigas que comumente perpassam o cotidiano das relações de amizade na adolescência se relacionam com a intensidade que essa relação apresenta nesse momento. Na adolescência as relações de amizade costumam ser mais intensas, sendo íntimas e provedoras de apoio, onde existe uma necessidade de lealdade mutua (FONTES, UZEDA, 2012).

Outro aspecto que também foi abordado na temática amizade foi à questão dos chamados "maloqueiros", sendo que alguns adolescentes dizem que os mesmos estão presentes no bairro onde moram. Ao fazer este relato Maria Bethânia é questionada:

Pesquisador(a): Tu tem amigos maloqueiros?

Maria Bethânia: tenho, bastante.

Pesquisador(a): Como que são teus amigos maloqueiros?

Maria Bethânia: eles são folgados, eu acho que eles tem deficiência mental (...) a gente não gosta de casqueiros, gente com deficiência metal.

Outros participantes também comentam sobre a presença desses "maloqueiros" no lugar onde moram:

Maria Rita: Eu moro numa rua que é bem na esquina de um bar, daí todo fim de semana nesse bar tem festa, daí teve um cara que foi pegar o lixo e daí apareceu outro 
cara que começou a espancar esse que tava catando o lixo (...) a umas duas semanas passadas teve três viaturas da policia lá, e eles pegaram e foram lá perto da minha casa, cheio de policial.

Pesquisador(a): Como é para vocês isso? O lugar onde vocês moram também é assim? Não tem barulho? Como que é?

Caetano: lá é só maloqueiro

Pesquisador(a): Quem é maloqueiro para você?

Caetano: é guri folgado. (...) são bem folgados, ficam mexendo com os outros." (...) "porque eles puxam encrenca.

Diante das percepções de Maria Rita e Caetano, identificam-se sentidos diferentes dos apresentados por Maria Bethânia, visto que os primeiros consideram a presença dos "maloqueiros" como um fator negativo, gerador de brigas e "encrencas", enquanto Maria Bethânia percebe os "maloqueiros" como parte de sua rede de amigos, mesmo descrevendo-os como casqueiros, folgados e com deficiência mental.

Além disso, as descrições que os(as) adolescentes fazem sobre esses grupos de pessoas com quem convivem no bairro onde moram, também trazem informações sobre esse território e é importante destacar a presença de menções à situações de violência, brigas de rua, intervenção policial e espancamentos que parecem constituir a rotina desses espaços e a vida cotidiana dos(as) participantes que trouxeram esses relatos.

Quanto às atividades que os adolescentes realizam com seus amigos, Meeus (1999 apud ANTUNES, FOINTAINE, 2005) constatou em suas pesquisas que a relação com os pares na adolescência está mais focada nas áreas e atividades de lazer e socialização. Nesse sentido, os participantes da pesquisa discutem sobre seu cotidiano, as atividades e brincadeiras que realizam junto com seus colegas e amigos:

Gal Costa de 12 anos escolheu a música "amigo pela fé" de Luan Santana, dizendo que a letra fala sobre amigos verdadeiros, da escola e da instituição (...) com meus amigos a gente dança, faz aula de dança juntos, de hip hop e balé.

Outros colegas também complementam relatando as atividades que realizam com seu grupo de amigos:

Cássia Eller: ah, a gente brinca assim, na rua aonde eu moro, jogo bola, vôlei.

Pesquisador(a): e o que vocês fazem para se divertir?

Marisa Monte: conversa, escuta musica (...) a gente brinca de bicicleta, vai à praia. 
As atividades realizadas pelos(as) adolescentes em seu cotidiano demonstram que o grupo pesquisado está vivenciando uma fase com características comuns, onde se realizam brincadeiras, como jogar bola e andar de bicicleta, além de ouvir música e ir à praia, sem relatar que frequentam casas noturnas ou baladas, também comuns na adolescência. Nesse sentido se faz importante considerar que os(as) adolescentes entrevistados(as) têm a média de 13 anos de idade, estando no final da infância e inicio da adolescência.

Percebe-se também, que os(as) entrevistados relatam pontos consensuais em suas rotinas e atividades realizadas com seus amigos, considerando que os adolescentes, em geral, buscam amigos que tenham atitudes e pensamentos com os quais se identifiquem, buscando construir uma relação de confiança que, muitas vezes, não encontram no contexto familiar (FONTES, UZEDA, 2012).

\section{Família}

De acordo com Dessen e Polinia (2007) a família se faz presente, de diferentes formas e configurações, em todas as culturas e sociedades, desempenhando o papel principal de mediar os padrões, modelos e influências culturais e de assegurar o bem estar e proteção de seus membros, por meio da transmissão de crenças, valores, ideias e significados sociais.

No que refere-se às configurações familiares, estas têm se transformado de acordo com as relações que se estabelecem na sociedade atual, nas quais não existe uma configuração familiar ideal, visto que as combinações de formas de interação entre os sujeitos que constituem os diferentes tipos de famílias contemporâneas são inúmeras, envolvendo a família nuclear com a presença do pai e da mãe, as recasadas com a presença de padrasto ou madrasta e, por vezes, de seus filhos de outros relacionamentos, as monoparentais, casais homossexuais, crianças que vivem com outras(os) cuidadores(as) que não são pai e/ou mãe, como avós, por exemplo, etc. (STRATTON, 2003 apud DESSEN; POLINIA, 2007).

$\mathrm{Na}$ pesquisa com os(as) adolescentes foi possível constatar esse aspecto, visto que percebeu-se uma configuração familiar bastante variada, envolvendo pais separados, adolescentes que residem com irmãos, com avós ou com pais casados. Alguns participantes trouxeram relatos sobre a separação de seus pais, mostrando que essa situação é geradora de mudanças, conflitos e sofrimento: 
Maria Rita: É que meus pais são separados, e no tempo em que eles eram casados ainda a minha vida era muito boa, tudo muito doce, eu andava nas nuvens, tudo muito doce, muito bom, mas daí acabou que eu fui crescendo fui começando a ver a vida no jeito que ela é, quando meus pais se separaram eu comecei a ficar amarga" (...) "daí se separaram e depois daí começou a ficar ruim porque daí começaram a brigar pela minha guarda e pela guarda do meu irmão, daí começaram a falar que um não iria ver a gente, essas coisas sabe? Mas daí depois começaram se separaram, mas ficaram brigando na justiça.

No posicionamento de Maria Rita, a respeito da separação de seus pais percebese a presença da alienação parental na disputa pela guarda dos filhos, além dos conflitos e mal estar que essa separação causou para a adolescente. Na adolescência é comum o aparecimento desses conflitos familiares, porém eles não são inteiramente negativos, visto que se fazem importantes no processo de construção de identidade e da formação dos valores do sujeito (FONTES; UZEDA, 2012). Mas no caso relatado pela entrevistada, esses conflitos foram encarados de forma negativa pela participante, que presenciou a disputa dos pais pela sua guarda, a continuidade das brigas e conflitos familiares e mesmo a situação de alienação parental onde a proibição de a criança ver ou conviver com o pai ou a mãe pode gerar sentimentos de medo ou abandono.

Os relatos dos participantes também envolvem situações de mortes de familiares:

Maria Bethânia: minha vó, teve o enterro dela, eu e minha mãe a gente não sentia mais as pernas quando chegou o caixão, ela já era velha, tinha ataque epilético, daí eu não senti mais as pernas.

Pesquisador(a): Daí o que mudou na tua vida?

Maria Bethânia: muita coisa, porque antes quando não tinha nada para fazer eu ia lá limpava a casa dela, fazia essas coisa, um monte de coisas, as vezes eu ia lá e fazíamos bolo, essas coisas (...) agora não tem nada para fazer. Eu fico no quarto dos meus pais. (...) Eu faço o quarto deles virar um lixo, dos meus irmãos, da sala e da cozinha.

Considerando as atitudes de Maria Bethânia de fazer os cômodos de sua casa "virarem um lixo", afirmando não ter nada para fazer devido a falta da companhia de sua avó que faleceu, percebe-se que perdas de familiares, assim como a separação dos pais, são fatores capazes de causar sofrimento e mudanças na vida e no cotidiano do adolescente, fazendo com que, muita vezes, ele se expresse por meio de rebeldia e de 
atitudes violentas. É importante destacar também, que, de acordo com o relato da entrevistada, essas atitudes parecem estar relacionadas com a sensação de tédio por não se ter nada para fazer e com a falta de relações sociais com que se possa interagir e fazer atividades cotidianas, considerando que a avó com quem ela fazia essas atividades não está mais presente; esses fatores enfatizam ainda mais a importância de instituições que visem promover atividades de educação, lazer e cultura para esse público jovem, como é o caso da instituição frequentada pelos(as) participantes em contra turno, na qual foram coletados os dados para a presente pesquisa.

Outra questão que envolve mortes na família e mudanças no cotidiano e nos hábitos de seus membros é o envolvimento dos familiares com crimes e situações de violência, que aparece novamente como um contexto presente na vida dos(as) participantes:

Maria Rita: (...) o meu tio deu uma briga, e meu tio acabou matando um bandido, daí ele foi chamado pela policia porque meu tio matou um bandido, daí meu tio ficou uma semana preso, depois meu tio foi solto, daí a policia mandou ele morar em outra cidade, só que daí em outra cidade iriam matar ele do mesmo jeito, daí era lá mesmo em São Paulo meu tio foi morto, daí eu fui lá e minha família foi lá, daí passou um tempo e mataram meu outro tio, daí minha vida ficou de cabeça pra baixo, daí meu pai, e meus primo assim não foram nem no velório aonde ele morreu, porque os bandidos tavam ameaçando falando besteira, e falaram bem assim pra minha mãe que invejavam meus tios e meu pai porque eles eram muito honestos e que eles não gostavam de gente assim por isso que eles queriam matar, daí para não acontecer com meu pai, era pra gente se mudar para mais longe possível daí a gente chegou aqui, (...) daí depois que eu vim pra cá a minha vida começou a ficar mais diferente, porque antes quando eu morava em São Paulo era tudo tudo... muito assim, daí depois que eu vim para cá, os parentes começaram a ficar mais distantes daí era muito difícil, porque a gente era muito unido

Gal Costa: É assim oh, meu pai e minha mãe faziam algumas coisas estranhas, $e$ eu não gosto disso e agora eles não fazem mais, quando eu tinha 7 anos, ele tinha sido preso daí quando eu diz 10 ele saiu da prisão, porque eu fiquei triste eu fiquei quase duas semanas chorando, é por isso que uma parte foi triste e a outra não.

Percebe-se que o envolvimento dos familiares com crimes, tráfico de drogas e situações de violência e assassinatos é presente na vida dessas adolescentes, essa situação envolve sentimentos de tristeza, conflitos e mudanças inesperadas na vida das 
entrevistados, que acabam por gerar o afastamento de familiares e antigas redes de apoio, o enfretamento da morte precoce de familiares e até mesmo a ausência paterna devido à sentença de prisão.

A morte de familiares também repercute em outras situações conflitantes, como intrigas familiares, envolvendo a divisão de posses e questões que envolvem herança e dinheiro:

Maria Bethânia: quando a minha avó morreu a minha tia enchia com minha mãe vender o terreno, a minha vó não era retardada não era nada dessas coisas, ela era epilética e ela passou o terreno para a minha mãe. E tinha uma casinha lá pra ela não tem daí ela faz o que ela quer do jeito que ela quer não tem daí essa briga, daí depois que ela morreu, elas ficam brigando por uma merreca de dez mil reais, ficam brigando por nada achando que dinheiro é tudo que trás felicidade e eu também não falo mais com ela porque minha tia é muito falsa, muito nojenta, eu nunca vou com a cara dela, eu só falava com ela por causa da minha mãe, agora não falo mais nada, é oi, tchau e deu.

Esses conflitos entre os familiares - no que diz respeito à posse de bens e heranças - envolvem o adolescente que presencia a situação e compartilha dos sentimentos e discórdias que são gerados nessas "disputas". Situações como essas distanciam o adolescente de seus familiares, como percebe-se na fala de Maria Bethânia que afirma não falar mais com sua tia, descrevendo-a como falsa e nojenta.

Outro aspecto presente na fala da adolescente trata da sua percepção sobre o dinheiro. Maria Bethânia afirma que os dez mil reais pelos quais sua família disputa são uma "merreca" e que sua família pensa que dinheiro é tudo e traz felicidade. Nesse sentido é interessante refletir sobre a concepção dos adolescentes sobre felicidade, percebendo que o sentimento de felicidade se encontra cada vez menos relacionado com a posse de bens materiais, diferente da visão da sociedade de que os adolescentes são materialistas e consumistas, como referido por Silva (2009).

As regras impostas pela família também são geradoras de conflitos, principalmente no que diz respeito à relação dos adolescentes com seus pais. A fala dos participantes envolve o sentimento de desconforto diante dos pais, um sentimento causado pela presença de regras e normas na família. Os participantes revelam que têm atitudes diferentes na presença e na ausência de seus familiares. Um dos momentos em que se evidencia esse aspecto é quando Maria Bethânia é questionada sobre como se sente perto de seus pais, devido a um trecho da música de Luan Santana que escolheu: 
“perto de papai você é santinha, quando o sogrão não tá, você perde a linha", sendo que a mesma responde: Eu? bem estranha. (...) Porque meu pai é muito chato, quando ele ta perto eu não posso ser quem eu sou, mas quando ele não esta perto eu sou quem eu sou (...). Ele não deixa eu escutar as músicas que eu gosto, mas a minha mãe ela deixa porque ela diz que eu tenho que curtir minha vida em vez de ficar trancada que nem ela é com meu pai, daí eu sou assim.

Essas regras presentes na família são abordadas como um fator positivo em certos momentos:

Maria Rita: meu pai é muito ciumento, ele não é chato, eu entendo ele porque ele quer me proteger.

Dessa forma, percebe-se a diferença na percepção dos(as) adolescentes com relação às regras estabelecidas na família, enquanto alguns consideram-nas como algo positivo que funciona como fator de proteção, outros consideram-nas como um fator negativo, gerador de impedimentos e de brigas familiares.

Esses conflitos e intrigas no relacionamento dos(as) adolescentes com os pais, motivados pela presença de regras e normas, se estabilizam e diminuem com o passar do tempo, considerando que na adolescência o sujeito passa por uma busca de liberdade, auto-afirmação, uma necessidade em afirmar sua independência, se diferenciar e reconhecer a si como um ser único com identidade própria. Os conflitos se fazem presentes, em geral, quando os pais buscam manter uma educação conservadora, severa e autoritária, fazendo com que o adolescente internalize valores e costumes comuns da época dos pais, em contrapartida, o(a) adolescente rejeita essas regras, considerando que está saindo da infância e tentado ingressar na fase adulta. Essa rejeição do(a) adolescente causa mudanças em seu relacionamento com a família, a qual os vê como uma criança ainda dependente (FONTES; UZEDA, 2012).

No que diz respeito à análise das regras e normas que são impostas no contexto familiar, percebeu-se que os(as) adolescentes fazem considerações a respeito de mudanças sociais que impõem essa normatividade das relações. Nesse sentido, os(as) participantes abordam a mudança de hábitos e costumes com o passar do tempo e também falam sobre a mudança nas formas de relacionamento afetivo:

Chico Buarque: Agora mulher pode fazer sexo antes do casamento.

Pesquisador(a): Como assim?

Chico Buarque: Tem mulher que no namoro fazia sexo só depois do casamento, antigamente era assim né?! 
Pesquisador: E como que é hoje?

Chico Buarque: hoje é a maior safadeza.

Maria Bethânia: o relacionamento de hoje em dia é melhor que o de antigamente, porque hoje da para namorar antes do casamento, conhecer bem a pessoa, quem escolhe é a gente. (...) e pode escolher o noivo.

Percebe-se nessas colocações que Chico e Maria relatam fatos e situações de tempos passados que não vivenciaram, citando hábitos e normas desse tempo, como a questão do sexo após o casamento. A respeito desse tema, é interessante perceber que os(as) adolescentes relatam que antigamente a mulher - a mesma norma não é citada para homens, apenas a mulher é abordada - não poderia fazer sexo antes do casamento, mas agora a mulher pode, ao serem questionados sobre suas opiniões a respeito disso, Chico Buarque diz que é a maior safadeza, diferente de Maria Bethânia que considera os relacionamentos de hoje melhores, devido à liberdade de escolha do parceiro e para namorar antes de casar-se. Na fala de Chico Buarque "é a maior safadeza" identifica-se a presença relações de poder entre homens e mulheres, pautadas em valores sociais conservadores e patriarcais, onde ainda se vê como "safadeza" o fato de mulheres terem vida sexual antes do casamento, esses valores atravessam as gerações constituindo os sentidos que os(as) adolescentes dão as formas atuais de relacionamento.

Refletindo acerca das falas dos(as) entrevistados(as) é possível compreender que as redes sociais de apoio constituem as possibilidades de desenvolvimento do sujeito, formando os valores que elegem para mediar suas percepções de mundo e princípios e concepções que mediam suas escolhas, perspectivas de futuro e a forma como se relacionam socialmente.

\section{Considerações finais}

Com a realização da pesquisa foi possível identificar importantes fatores que compõem a forma como o(a) adolescente em condição socioeconômica desfavorável percebe sua condição de vida. Percebeu-se que a forma como eles(as) agem e se definem é constituída pelas relações que se estabelecem com suas redes de apoio social. Muitas vezes, essas relações são descritas como permeadas por diversos conflitos, como o envolvimento de familiares com a criminalidade e o tráfico de drogas e a presença de intrigas e desavenças entre membros da família. Esses fatores estão presentes em diversos ambientes, além do contexto familiar se estendem para o bairro e para a escola. 
Quanto à condição socioeconômica dos(as) participantes, identificou-se que a instituição da qual eles(as) participam tem como critério de atendimento que a família seja de baixa renda e em situação de vulnerabilidade socioeconômica, dessa forma, a maioria deles vivencia uma condição desfavorável no que tange ao acesso à educação, lazer, moradia e mesmo recursos básicos como alimentação, todos são estudantes de escolas públicas e entre as profissões dos pais dos participantes estão a de doméstica, zeladora, caminhoneiro, entre outras.

Foram identificadas também, várias referências à violência urbana e a criminalidade, as quais estão presentes tanto no contexto familiar, considerando as menções de envolvimentos de familiares com crimes e acontecimentos de mortes de familiares em situações de violência e assassinatos e, também no território em que vivem, onde existe proximidade com bares nos quais ocorrem brigas frequentes e com pontos de tráfico de drogas. Essa situação se evidenciou, inclusive, na fala de um dos participantes que relata a experiência de ter saído do estado onde morava para se afastar se um território perigoso, onde ele e sua família corriam risco de morte.

Outro aspecto evidenciado como causador de conflito aos(às) adolescentes, diz respeito à separação dos pais. Muitas vezes os(as) adolescentes vivenciam brigas em seus lares, desavenças entre seus pais e até mesmo a disputa pela guarda dos filhos. Essas situações às quais são expostos(as) causam sofrimento, pois os(as) participantes abordam esses assuntos em meio ao choro, se referindo a separação dos pais como um momento ruim de suas vidas, não exatamente pelo divórcio, mas sim pelo contexto de brigas recorrentes e alienação parental.

No que diz respeito ao contexto escolar, percebeu-se que a função de rede social de apoio da escola não foi explicitada nas falas dos participantes, esse espaço foi descrito como um local de interações com os colegas e de contestação de regras e normas. Assim percebeu-se um espaço escolar que se mantém distante da realidade e dos interesses dos sujeitos que ali estudam, onde não são mencionados vínculos de respeito e afeto com professores(as), os(as) quais não são percebidos(as) como educadores ou formadores de opinião.

Na coleta dos dados, a música apareceu como facilitadora para obtenção dos resultados, visto que beneficiou a expressão dos participantes motivando-os a falar e aprofundar-se nos significados que envolvem sua vida, seu cotidiano, seus hábitos e suas relações, sendo que muitas das falas analisadas na presente pesquisa partiram de 
reflexões e provocações geradas pelas letras de músicas que foram apresentadas no encontro.

Se faz importante considerar também, outras questões a serem abordadas em publicações e pesquisas futuras contendo os resultados das outras categorias que não foram abordadas aqui (percepção de si, percepção de tempo, território e comunicação). Para efeitos desse artigo, os resultados obtidos passaram por um corte temático, elegendo-se as redes sociais de apoio para serem apresentadas e discutidas. Outros aspectos também foram identificados nos dados coletados, visto que nas entrevistas os(as) adolescentes relataram fatores que envolvem o território onde vivem, as características deste espaço - físico, cultural e social - e as relações que se estabelecem neste, além de relatar as formas que utilizam para comunicar-se com o lugar que habitam e com a sociedade, entre as quais as redes virtuais foram abordadas com maior frequência; também foram identificadas as percepções dos(as) adolescentes a respeito do tempo e as transformações culturais que ocorrem em regras e hábitos majoritariamente vigentes e aprovados socialmente.

Esses dados que não foram explícitos, porém estiveram presentes - mesmo que não sendo aprofundados - no desenvolvimento do artigo, são tão relevantes quanto aqueles que foram abordados e discutidos no presente trabalho, podendo sendo foco de futuras discussões. Porém, considerando o recorte adotado e as reflexões acerca de relações sociais e redes de apoio construídas na vida dos(as) participantes é importante destacar ainda o quanto as relações com familiares, amigos(as) e com o território onde vivem impacta profundamente na constituição desses adolescentes, em suas percepções de sociedade e de si mesmo, em suas perspectivas de futuro e na habilidade que desenvolvem para enfrentar situações adversas e de sofrimento. Nesse sentido, o desenvolvimento de políticas públicas que pensem da forma mais ampla possível a qualidade de vida dos(as) jovens brasileiros(as) é de extrema importância, - que sejam capazes de pensar os mais diversos aspectos da vida humana: cultura, lazer, educação, moradia, alimentação, acolhimento psicológico e todos os aspectos citados pelos(as) entrevistados(as) como impactantes em suas vidas -, não somente importantes de forma individual para cada sujeito, mas para transformação social, inclusive impactando na diminuição dos índices de violência e criminalidade, fatores que apareceram de forma recorrente nas falas dos(as) entrevistados. 


\title{
SOCIAL RELATIONS AND SUPPORT NETWORKS IN ADOLESCENCE: REPORTING MEDIATED EXPERIENCES BY MUSIC
}

\begin{abstract}
The proposal of this paper is a result from a qualitative intervention research conducted with fifteen teenagers from an institution located north coast of Santa Catarina. For data collection, music workshops were made and the participants chose music lyrics that address questions about their life condition, talking about the place where they live, their perception of themselves, their perception of the time and of the social support networks. In a cutting theme for the proposes of this article, the social support networks were chosen as the theme to be analyzed and discussed by thematic-categorical analysis. The results pointed to a school area with an undefined function, based on the contestation of the rules and regulations that are imposed, where the games and intrigues happen. Referring to the friends network, observed that this relation is based on feelings of trust and loyalty, setting up as a essential network in the life cycle, as well as the family that presents itself as a protective factor, even through conflict situations, violence, deaths an separations.
\end{abstract}

Keywords: adolescence, life condition, social support networks; music.

\section{RELACIONES SOCIALES Y REDES DE APOYO EN LA ADOLESCENCIA: RELATANDO EXPERIENCIAS MEDIADAS POR LA MÚSICA}

\section{Resumén}

El presente artículo es el resultado de una investigación de intervención con enfoque cualitativo, realizada con quince adolescentes de una institución localizada en litoral norte de Santa Catarina. Para la coleta de dados fueron realizados talleres musicales, en los cuales los miembros preferirán letras de canciones que enfoquen cuestiones con respecto a su condición de vida, disertando sobre los lugares donde viven, la percepción que tienen de sí propio, del tiempo y sus redes de apoyo social. En un tema de corte para los efectos de este artículo, se eligieron las redes de apoyo social como el tema para ser analizado y debatido por el análisis de temáticas-categóricas. Los resultados apuntaron para un espacio escolar con una función indefinida, pautado en la contestación de las reglas y normas que son impuestas, donde hay juegos y chismes. Cuanto a la rede de amistades, se ha observado que esta relación se basa en los sentimientos de confianza y de lealtad, se perfila como una red esencial en el ciclo de vida, así como la familia es presentada como un factor de protección, incluso impregna situaciones contradictorias, con violencia, muertes y separaciones.

Palabras-llave: adolescencia; condiciones de vida; redes sociales de apoyo, música.

\section{REFERÊNCIAS}

ANTUNES, C. FONTAINE, A. M. Percepção de apoio social na adolescência: análise fatorial confirmatória da escala social support appraisals. Paidéia, Portugal, vol. 15, n. 32, p. 355-366, 2005.

BARBOSA, T. A. A Amizade É Tudo. Intérprete: BARBOSA, T. A. DIEGUES, B. In: 5 Elementos. São Paulo: Sony Music Entertainment, 2009. 1 CD e DVD. Faixa 13. 
BORSA, J. C. O papel da amizade ao longo do ciclo vital. Psico-UFS, São Paulo, vol. 8, n. 1.p. 161-162, 2013.

COSTA, L. G. A rede de apoio social de jovens em situação de vulnerabilidade social e o uso de drogas. Rio Grande do Sul. 93 p. Dissertação de mestrado - Programa de Pós Graduação em Psicologia. Universidade Federal do Rio Grande do Sul, 2009.

DAYRELL, J. A Escola “faz" as juventudes? Reflexões em torno da socialização juvenil. Educação Soc. Campinas, Campinas, vol. 28, n. 100, p. 1105-1128, Especial, 2007.

DELL'AGLIO, D. D.; SANTOS, L. L. Uma metodologia para pesquisas com adolescentes SM situação de rua: investigando o passado, presente e futuro. In: CASTRO, L. R.; BESSET, V. L. Pesquisa-intervenção na infância e juventude. Rio de Janeiro: Trarepa/FAPERJ, 2008.

DESSEN, M. A.; POLONIA, A. C. A família e a escola como contextos de desenvolvimento humano. Paidéia, Ribeirão Preto, vol. 17, n. 36, p. 21-32, 2007.

DO AMPARO, D. M.; GALVÃO, A. C. T.; ALVES, P. B.; BRASIL, K. T.; KOLLER, S. L. Adolescentes e jovens em situação de risco psicossocial: redes de apoio social e fatores pessoais de proteção. Estudos de psicologia, Campinas, vol. 13, n. 2, p. 165-174, 2008.

FONTES, B. C.; UZEDA, F. C. A. A adolescência: o processo de afastamento familiar versus tendência grupal e a construção da identidade. Revista Letrando, Bahia, vol. 1, 2012.

GALLO, D.. Amigos pela fé. Intérprete: SANTANA, L. R. D. In: Luan Santana Ao Vivo. Rio de Janeiro: Som Livre, 2009. 1 CD. Faixa 17.

GROFF, A. R. A mediação da música no MST: um estudo em contextos e eventos coletivos em Santa Catarina. Florianópolis. 122 p. Dissertação de mestrado - Centro de filosofia e ciências humanas - Programa de pós-graduação em psicologia. Universidade Federal de Santa Catarina, 2010.

INSTITUTO BRASILEIRO DE GEOGRAFIA E PESQUISA. Síntese de indicadores sociais: uma análise das condições de vida da população brasileira. Rio de Janeiro: IBGE, 2010.

O PENSADOR, G. Estudo Errado. Intérprete: O PENSADOR, G. In: Ainda É Só o Começo. São Paulo: Sony Music Entertainment, 1993. 1 CD. Faixa 6.

OLIVEIRA, D. C. Análise de conteúdo temático-categorial: uma proposta de sistematização. Rev. enferm. UERJ, Rio de Janeiro, vol. 16, n. 4, p. 579-576, 2008.

OZELLA, S. A adolescência e os psicólogos: a concepção e a prática dos profissionais. In: OZELLA, S. (org.). Adolescências construídas: a visão da psicologia sóciohistórica. São Paulo: Cortez, 2003. 
PRATTA, E. M. M.; SANTOS, M. A. Família e adolescência: a influência do contexto familiar no desenvolvimento psicológico de seus membros. Psicologia em Estudo, Maringá, vol. 12, n. 2, p. 247-256, 2007.

SANTANA, L. R. D.; CALIMAN, B.; ARAÚJO, M.; SAVATTI, G. Sogrão Caprichou. Intérprete: SANTANA, L. R. D. In: As Melhores... Até Aqui. Rio de Janeiro: Som Livre, 2013. 1 CD. Faixa 14.

SILVA, R. A. O futuro é violento: Sobre perspectivas de futuro para jovens de ensino médio e ingressantes de curso superior. Revista FACEVV, Vila Velha, n. 2, p. 57-62, 2009.

SIQUEIRA, A. C. Escola como parte da rede de apoio de adolescentes em reinserção familiar. VIDYA, Santa Maria, vol. 29, n. 2, p. 87-96, 2009.

WAZLAWICK, P. Música e vida em criação: dialogia e est(ética): A música de um duo de violóes. Florianópolis. 337 p. Tese de doutorado - Centro de filosofia e ciências humanas - Programa de pós-graduação em psicologia. Universidade Federal de Santa Catarina, 2010.

Data de recebimento: $23 / 10 / 2013$

Data de aceite: 10/11/2020

\section{Sobre os autores:}

Janaina de Fátima Zdebskyi é Graduada em Psicologia pela Universidade do Vale do Itajaí; Bacharel e licenciada em História pela Universidade Federal de Santa Catarina; Mestra em História Cultural pela UFSC e doutoranda em História Global pela UFSC, com pesquisas sobre História Antiga/Mesopotâmia, mitologia, História das religiões e religiosidades e gênero na antiguidade. Endereço Eletrônico: janinha10008@hotmail.com

Carlos Eduardo Máximo possui graduação em Psicologia pela Universidade do Vale do Itajaí (1992) e mestrado em Psicologia pela Pontifícia Universidade Católica do Rio Grande do Sul (1999). Atualmente é professor titular da Universidade do Vale do Itajaí, com experiência na área de Psicologia Social. Participa de programas de formação profissional em saúde como o PRO-SAÚDE II e o PET-Saúde multiprofissional. Cursa o doutorado em Psicologia no Programa de Pós-graduação em Psicologia da Universidade Federal de Santa Catarina. Endereço Eletrônico: carlosemaximo@gmail.com

Ulysses Thiago Batista Pereira possui graduação em Psicologia pela Universidade do Vale do Itajaí. Endereço Eletrônico: ulysses-15@hotmail.com 